ity. When first announced it was said that it would be a "second Harwell" and that it would provide scope for work on reactor development. Development of the site started in September 1957, and one of the first projects is the construction of a hightemperature gas-cooled reactor.

\section{British Ballistic Missile fired from Woomera}

A BrITish 'Black Knight' ballistic missile was successfully launched to a height of 300 miles from Woomera rocket range on September 7. The Australian Minister of Supply, Mr. Atholl Townley, who was at Woomera to see the launching, is reported to have said that the rocket performed according to expectations. The 'Black Knight' is a purely research vehicle, and observations of the behaviour of the rocket engine, control and guidance mechanisms, together with measurements of its environment and other phenomena, were made continuously while it was in flight and relayed to ground receivers from several transmitters installed in the missile. Its behaviour during re-entry into the Earth's atmosphere was also recorded; the nose-cone has been recovered. The 'Black Knight', which is about $35 \mathrm{ft}$. long and $3 \mathrm{ft}$. in diameter, was largely developed and built by Saunders-Roe, Ltd., in co-operation with the Royal Aircraft Establishment. Static firings were made at Highdown, on the western tip of the Isle of Wight. The rocket engine was built by Armstrong-Siddeley Motors, of Coventry, to an original design of the Rocket Propulsion Department of the Royal Aircraft Establishment at Westcott.

\section{Swedish National Committee for Physics}

THE ninth general physics conference of the Swedish National Committee for Physics was held at the University of Uppsala during June 3-5, 1957, and a brief report of the meeting together with abstracts of the large number of contributed papers is printed in the March issue of Arkiv für Fysik. $(13,251 ; 1958)$. Guest lectures were given by M. A. Melvin (Florida State University), who spoke on conservation-invariance principles and the behaviour of elementary particles, and by $H$. Palevsky (Brookhaven National Laboratory), who discussed the use of cold neutrons to investigate the solid state.

The majority of the contributed papers deal with aspects of nuclear physics, but there were several survey articles or lectures of general interest. $H$. Conde discussed the generation and measurement of high thermal radiation intensities, and E. Djurle and W. S. Rodney instrumentation for phase contrast measurements in the near infra-red. A brief survey of present-day knowledge of the elementary particles and of their transformations was given by $\mathrm{S}$. von Friesen, and an account of the proposed new physics building for the University of Stockholm, which is expected to be ready for use in $1959 / 60$, by $\mathrm{E}$. Hulthen. A description of the Uppsala Ionosphere Observatory was given by W. Stoffregen. Its geographical situation is near the auroral zone and instruments for ionospheric research and an all-sky aurora camera are in operation at the observatory. The ionospheric recorders, or 'ionosondes', designed and constructed at the observatory, consist of a radio pulse transmitter and receiver, together with oscillograph units for photographic recording of the radio echoes, and they make vertical soundings of ionized layers of the atmosphere. For study at oblique incidence by means of backscatter, a rotating beam antenna is used and reflexions up to $2,000 \mathrm{mk}$. distance can be received. Since January 1957, a secondary station has been in action at Lycksele, about $500 \mathrm{~km}$. north of Uppsala, and six aurora cameras are also operating at places between Uppsala and Tromsö.

\section{Institution of Metallurgists Handbook}

DURING the first quarter of the present century, more metal was produced and used throughout the world than during the whole of previous historic time. This growth in the practice of metallurgy demanded a body of trained and qualified metallurgists. It is, however, barely a dozen years ago since the Institution of Metallurgists was founded to meet this need. Its first object is "to advance and co-ordinate the study and science of metallurgy in all its aspects". In so doing, the Institution clearly serves the public interest, not only by certifying the scientific or industrial qualifications of its members, but also by its work, for example, in connexion with National Certificates in its subject. That a need for such an Institution existed and that it is serving the purpose for which it was founded is abundantly demonstrated by the growth of its membership, a growth which surprises even the most sanguine of its founders.

In its new form, the Year Book and List of Members for 1957-58, published for the Institution by Batiste Publications, Ltd., gives expression to the increasing prestige which the Institution enjoys and deserves. In addition to the list of officers and members and the conditions under which admission to the various grades of membership may be obtained, 75 pages are devoted to short technical articles dealing with the more important of the individual metals. In the space available these articles cannot, of course, be exhaustive, but they are very far from being superficial and the data contained are authoritative. In a foreword, Mr. James Mitchell, the president at the time this handbook was prepared, summarizes the aims of the Institution, aims which in a large measure, at any rate, have been attained, in the following words: "The Council of the In. stitution are most anxious that its membership should include all practising metallurgists who have the necessary qualifications, but they are insistent that a high professional standard must be maintained and they take this to include not only technical qualifications and experience but the observation of high ethical standards".

\section{Careers in the Medical Research Council}

UNDER the title "Technical Careers in the Medical Research Council" (pp. 31. London: Medical Research Council, 1958), the Medical Research Council has issued a brochure giving a concise but clear picture of the opportunities which are open as technical officers or technicians in the service of the Council. The Council's staff of 2,152 (only 121 of whom are part-time) comprises 224 medically qualified, 424 scientifically qualified and 91 technical officers, with 690 other technical staff, 332 maintenance and 391 administrative and clerical staff. Besides information about the general conditions of service, a brief survey of the types of work undertaken in the Council's establishments and a note on the qualifications required for entry to the various grades, the booklet includes a survey of the research programme under the main scientific headings and an alphabetical list of the Council's establishments and their addresses, which make it useful to a wide range of scientific workers. 